\title{
Lagartos na sombra (Miserias de poeta)
}

\author{
Modesto Hermida
}

regomazaira@hotmail.com

\section{PLURALIDADE CONCEPTUAL}

Semella conveniente, como consideración previa a este traballo de subxectiva opinión, achegar unha síntese dos posibles significados do substantivo miseria, do cualificativo miserable e dalgunhas das varias acepcións que se lle poden adxudicar a esta familia léxica, a este correspondente semantema.

$\mathrm{O}$ vocábulo miseria en ben moitos casos fai refeencia á desgraza, ó infortunio; unha acepción esta na que o significado aparece como universal, menos marcado, menos coutado, menos directamene referido a unha matizada concreción da realidade. Con todo, non cabe dúbida de que, de non facermos un esforzo de precisión semántica adecuado, dado que o exercicio da poética, da expresión poética, pode arrastrar o practicante ó infortunio, ou mesmo á desgraza, con maior probabilidade do que á felicidade material, a ese éxito social que prende no bucle da suficiencia económica, ben se podería entender, de non mediar outra reflexión, que esta é a acepción que mellor acaería para un título coma o que utilizamos.

A acepción máis lóxica dende a estricta observación da lóxica lingüística e aquela que nos indica a estreiteza de recursos, a falta do que resulta máis necesario para unha digna subsistencia, en definitiva, aquela que proclama a extrema carencia. Non temos dúbida de que poetas houbo, hai e haberá nos séculos vindeiros anavallados por esta desgraza da carencia de recursos, pero tamén sabemos ben que non é desgraza esta da exclusividade dos poetas nin, se cadra, desgraza que incida con maior virulencia nos amantes da confección do verso ca noutras tipoloxías sociais, profesionais ou artísticas. En liña con este central significado podería estar o uso do vocábulo cando nos referimos a algo escaso, insuficiente, non satisfactorio para o beneficiario; así, consideramos cantidades insignificantes, miserables, as que non cobren necesidades nin expectativas. Claro que vivir miserablemente, que pode considerarse dende a loxicidade lingüística co significado de vivir con estreiteces de recursos, en moitas ocasións e alén de vivir voluntariamente por baixo das propias posibilidades, nunha linguaxe máis figurada é vivir na miseria psicoafectiva, vivir á marxe das virtudes éticas, á marxe do que se entende como limpeza de espíritu e, precisamente, nesta miseria é na que nos semella, sen entrarmos agora nas razóns ou senrazóns, que caen moitos máis poetas, poetas de mérito, dos que sería desexable e dos que as boas xentes consumidoras de poesía poden chegar a intuír, pois a beleza, a calidade do verso, do poema, disfraza ou acubilla certas miserias, que son as limitacións psíquicas e cívicas do poeta. Curiosa acepción, que nada ten que ver de modo especial cos poetas no seu lóxico significado (cuestión á parte sería, outra volta, nun significado figurado), é a acepción de piolloso, xa que miseria pode significar-observado este significado por tódolos diccionarios- praga pedicular, que non é outra cousa que praga de piollos. 
$\mathrm{O}$ que agora ten fundamental interese para o desenvolvemento deste modesto ensaio son os significados con referencia á avareza e á mezquindade (retomemos para este parágrafo aquel significado adxectival, máis figurado, que era o de de vivir miserablemente). Se consideramos o termo avareza no senso material, como desexo desordenado de acumular como bens de consumo ou para o posible consumo, diñeiro e riquezas varias, non encontrariamos entre as hostes do parnaso excesiva porcentualidade de avarentos, pero se expandiramos a semántica do significante a unha avareza de ser, de preponderar no universo das musas, de figurar con distinción sobre o colectivo doutros practicantes do oficio, aí si que xorde o vezo como pandemia, de tal maneira que sería máis doado contabilizar os humildes e limpos de corazón ca os afectados da enfermidade; e non proceden moitas distincións entre poetas de oficio real, con obra de mérito, e vocacionais carentes de talento para crear o sublime texto con plurivocidade poética. Nesta liña, a mezquindade vén a ser o resultado, a consecuencia, malia que ás veces causa, desa desmedida avareza, por veces estética tamén, de ser, de representar, de ter recoñecemento, de ser casta distinta á grei incapaz, mortal e afastada dos deuses.

Miseria é vocábulo usado con frecuencia polos poetas que foron e que son; uso, por certo, en diversas circunstancias e con moita diversificación de significados, tanto lóxicos coma figurados, fundamentalmente para denunciar a obxectiva miseria e clamar contra tódolos miserables de espírito. Resultaría tan impertinente coma imposible facer un repaso textual desta utilización sobre toda a produción poética do noso ámbito cultural pero, por facer presentación e mostra somera, referiremos esta pequena escolma: Larra ironiza, con intencións pouco xenerosas, sobre aqueles que, con descoñecemento absoluto desta virtude, seguramente na condición de secaños miserables, se ocupan en contar as miserias alleas. "Oh miseria, quien puede contra ti", versifica o xove venezolano Rod Medina en moderna utilización do verso. $\mathrm{O}$ arxentino César Portela titula "Miseria" un seu poema. $\mathrm{O}$ xove bilbaíno residente nalgún lugar de
Andalucía, Daniel Barredo, dedica un poemario completo a este diversificado concepto co título Oda a la miseria. Outro libro de poemas é a contribución de Fernando Rojas, o Premio Cervantes chileno, que nos seus inicios como poeta publica La miseria del hombre. "Me siento espectador de mis miserias" é o primeiro verso dun soneto do canario Luís Pérez e "La gran miseria humana" é o título dun poema do colombiano Gonzalo Escorcia Gravini. Miseria e fame combatida con cebola foi a que sufriu Miguel Hernández porque, no intenso sufrimento da súa circunstancia aferrollada, era o seu fillo acabado de nacer, de famenta nai, quen sufría as carencias de alimento. En "A un poeta muerto", Cernuda expresábase liricamente deste modo:

\section{Triste sino nacer con algún don ilustre aquí, donde los hombres solo saben el insulto, la mofa, el recelo profundo ante aquel que ilumina las palabras opacas por el oculto fuego originario}

Velaí, xa que logo, a denuncia desoutra tan traicioneira, tan destrutiva miseria. Miseria, vivencia tan do universo íntimo de tantos poetas, palabra tan do uso deles, desgraza tan contestada verso a verso, estrofa a estrofa, poema a poema. Valente, nalgún dos seus arroutos líricos, escribiu "poeta en tiempo de miseria, en tiempo de mentira/ y de infidelidad". O logroñés Paulino Lorenzo versifica unha miserable candición e actitude cos versos "Corazón de poeta/ que por media peseta/ te vendes al más necio...".

Entre os poetas galegos, máis ca recreadores do vocábulo, encontraremos denunciadores da circunstancia, denunciadores de tódolos desarranxos que carrexa a inxusta realidade da miseria. Non hai mellor síntese deste panorama que a constancia do xeralizado combate, palabra por palabra, contra todo panorama miserable; desolado panorama no que ten sido tan abondosa en espazo e en tempo a patria galega, a lingua galega, ese motivo e musa, ademais de código, en tantas ocasións para os poetas nosos: Rosalía, Curros, Celso Emilio e unha lexión con eles, de antes e de agora, que sempre acudiu ó compromiso. Exemplo de 
sufridor da miseria témolo en Añón, ciudadano e poeta de condición nada miserable, xa un dos heroicos iniciadores na recuperación da conciencia de noso. Noutro senso e significado ten utilizado o vocábulo, con nidio significado de navalla ben aguzada, o grande Poeta Méndez Ferrín, cando arremeteu, pode que non libre de miseria, contra outro excelente e intenso lírico, Antón Tovar, con ocasión de reprocharlle a escaseza de léxico ("léxico miserable", acusaba), no seu corpus poético.

¿Para que poetas en tempos de miseria?, seica dicía Hölderlin dinantes de cruzar o Rubicón da razón. Esta retórica interrogante serviulle de moi adecuado título e fundamento ó venezolano Rafael Ratia para tracexar un artigo de alta calidade formal, se cadra non alleo á miseria en relación ás mensaxes emitidas, para criticar a actualidade chavista no seu país mediante unha clasificación dos "escribidores" daqueles pagos, afectados, segundo el, de moi diversas miserias, sen que sexa menor a miseria que se desprende da vasalaxe, postulado dende o que conclúe na inutilidade da poética nestes tempos que considera miserables. Nós, que non sabemos moi ben no que poidamos coincidir con Hölderlin nin temos unha actitude moi negativa sobre a revolución bolivariana, consideramos que en tempos de miseria real a poesía pode ser adecuada para a denuncia, pode ser calmante, cauterizante (se cadra, estupefaciente; é un perigo inevitable), pode axitar conciencias e multiplicar o compromiso en individuos e en intensidade, pode adornar a fealdade dos panoramas e manter viva a esperanza. Claro que, de non ser inxenuos, aínda que non sexa estorbo, sabemos que non é na poesía, como xa se ten indicado, onde hai que fundamentar as posibilidades da redención da miseria, da redención dos males que afronta a humanidade.

\section{RADICAIS EXEMPLOS E OPINIÓNS}

Oscar Wilde, no capítulo IV da novela $O$ retrato de Dorian Gray (The picture of Dorian Gray), preséntanos un significativo diálogo entre os personaxes Harry (Henrry) e mailo seu pupilo Dorian Gray, con ocasión de emitir este último a súa opinión sobre o artista plástico Basil. Harry, dende a súa experiencia, déixalle clara constancia de que os únicos artistas persoalmente encantadores que levaba coñecido eran malos artistas, namentres que os bos artistas, que tan só existen no que como tales fan, carecen, en consecuencia, de interese como persoas, como suxeitos. En relación ós poetas, chega a manifestarse da seguinte maneira:

Un gran poeta, un verdadeiro gran poeta, é a menos poética das criaturas. En cambio, os poetas menores son completamente deliciosos. Namentres peor son as súas rimas, máis pintorescos semellan eles. O mero feito de ter publicado un volumen de sonetos de segunda man, fai irresistible a un home. Vive a poesía que non pode escribir. Os outros escriben a poesía que non se atreven a levar a bon término (a cabo).

Nesta liña de ensinanzas, Lord Henry chega a postular que a vida, nas personalidades complexas, ten tamén as súas obras mestras, da mesma maneira que as artes (poesía, escultura ou pintura) teñen as súas propias obras mestras. Esta xeralización que postula Wilde, dende as palabras do seu personaxe de ficción, cómpre atemperala para que a poidamos tomar como opinión considerable; claro que a súa visión parte da particular experiencia e, con toda probabilidade, parte de razón non lle faltaría.

Sen saírmos do universo literario anglosaxón, acudimos a unha das últimas columnas do inesquencible Carlos Casares, daquelas que publicaba en $\mathrm{La}$ Voz de Galicia co título de sección "Á Marxe", na que nos conta como, ó pouco de morrer Lord Byron, reunidos o editor e mailos familiares do escritor, xa falecido este, nun cuarto de Londres con cheminea, decidiron queimar as memorias do difunto. Dende tal acontecemento parece que teñen sido ben moitos os que lamentaron aquel acto de censura, quen máis entre todos o amigo que recibirá o encargo de vender aquela morea de papeis. Pero o que importa para o caso que nos ocupa e que, sen memorias e todo, ninguén dubida das miserias de Byron, das que deixou abondosa constancia nas cartas dirixidas ós amigos. Carlos Casares fai referencia á biografía do famoso escritor publicada no ano 2000, da autoría da americana Benita Eisler, na que presenta a un home horrible coa condición de xenial poeta. Con todo, as atrocidades 
de Byron debían de pertencer a un individuo con certos encantos, xa que, tanto a súa esposa Annabella coma a súa irmá Augusta, da que por incestuosa relación nacera a meniña Ada, nin lle debían querer mal nin lle debían ter ningún tipo de inquina, pese a telas xuntado a ambas en repetidas ocasións para que o agasallasen, a un tempo, cos seus agarimos e cos seus abrazos. De todo esto, como xa nos indicaba Carlos Casares, dedúcese algo enigmático e inquietante, o feito de que, ó mesmo tempo, uns canallas malvados non carezan da necesaria sensibilidade para escribir excelentes versos. Con semellante reflexión final, case estou seguro de que Carlos Casares non só apuntaba ó nobre inglés de tempos pasados, senón que incluía a algún dos poetas máis próximos ó seu tempo e ó seu universo social, literario e cultural, tipos capaces de alcanzar a excelencia poética sen teren nin chisca de respectabilidade como persoas.

Nunha columna de redacción, de carácter informativo, nun xornal madrileño, dábase conta das palabras do incisivo escritor Francisco Umbral (Francisco Alejandro Pérez Martínez), a quen, para minorizalo, a pintora Antonia Dans lle chamaba Paquiño: na Semana Poética dun dos cursos de verán en San Lorenzo del Escorial, na disertación que levaba por título "Los poetas, esos monstruos sensibles", opinaba que nada pode purificar tanto unha boa poesía como pode unha mala vida. Non sabemos moi ben a que se refire Fancisco Umbral con "una mala vida": vida disipada, disoluta, ou vida de baixa calidade existencial, de baixa capacidade de consumo; vida bohemia, en todo caso. O que si coñecemos é o seu aprecio polos poetas malditos, co que carrexan de malalinguas e de baixa calidade de vida, segundo os parámetros burgueses, pero que atesouran, en moitísimos dos casos, unha extraordinaria poética, poñamos por caso, dende Frances Villón a Carlos Oroza; poetas estes malditos que formulan con toda claridade o contraste entre a mezquindade da que pende a existencia humana e a condición sublime que corresponde á poesía. Semella que Umbral non aprecia ou non se quere decatar do divorcio entre a sensible condición do poeta e a excelsitude da súa obra; máis ben todo fai pensar que pretente confrontar a bastardía dos comportamentos da masa social coa luminosidade do texto poético, outra das miserables relacións que, á fin e ó cabo, sofre o universo da liricidade.

\section{UN ANECDOTARIO ILUSTRATIVO}

Máis puntos de vista sobre algunhas das miserias dos poetas, dos escritores en xeral pero especialmente dos poetas, podería ser a opinión que, tácita ou afiadamente expresa, sincera ou non, teñen uns colegas dos outros, mesmo cando exercen o oficio de críticos literarios. Nun moi interesante libro de 1990, El ojo crítico, o recoñecido analista da literario Constantino Bertolo recolle unha serie de equivocadas e inxustas opinións sobre excelentes escritores por parte dos seus colegas coetáneos, en moi diversos ámbitos lingüísticos e temporais, coas que se evidencian de forma clamorosa certas miserias de poetas que, dominados pola carraxe e pola envexa (miserias da peor calaña) ou afectados de ignorancia e de carencia de axustado ollo crítico (outra inxustificable maneira de miseria), teñen postulado supremas barbaridades. Bertolo achéganos dende o pasado máis ou menos afastado varios dos dislates da tipoloxía a que nos temos referido; a saber: Pío Baroja chegou a cualificar a Flaubert como animal de pata pesada; Zola dicía sobre Les fleurs $d u$ mal e do seu autor, Boudelaire, que en cen anos, para a historia da literatura francesa, tan só serán unha insignificante curiosidade; Lope de Vega manifestara que, entre os poetas "ninguno hay tan malo como Cervantes, ni tan necio como don Quijote"; Gongora, pola contra, dicía que os versos de Lope "son como los buñuelos, que enfriándose no vuelven a tomar la sazón de antes aunque vuelvan a la sartén"; namentres que Luzán, un autor que está nas orixes da teoría poética en castelán, consideraba extravagantes as metáforas de Gongora, consideración que, neste caso, por tratarse dun profesional da teoría e da opinión, a miseria semella máis froito dunha carencia de acerto ca doutros baixos e secos instintos. Fóra do ámbito das hispanas letras non faltan os mesmos tipos de despropósitos: Voltaire cualificaba o Hamlet como obra bárbara ou consideraba a 
Shakespeare comparable, como autor, a un salvaxe borracho. Non por máis comprensible, dada a revolución literaria que se xestaba, deixa de sorprender que Virginia Woolf anotara no seu diario que o Ulises (Ulysses) 1le parecese un fracaso, considerando universais os adxectivos aplicados á obra, como libro salobre, pretencioso e vulgar. De El ojo crítico fíxose eco Juan Cantavella nunha reseña xornalística na que considera escasamente consoladora, para tales despropósitos, a conclusión de Constantino Bertolo, moi de seguro chea de galega ironía, cando sintetiza a súa comprensiva actitude mediante o refrán castelán: "El que tiene boca se equivoca".

\section{ESTUDOS EXTRAPOÉTICOS CON RE- LACIÓN Á CONDICIÓN DE POETA}

De Xesús Valcárcel, o escritor de diversos xéneros, poeta de mérito, supoño que por termos dialogado sobre o tema, recibín, xa hai anos, a copia dun extenso artigo da psiquiatra Myrian López Blanco, publicado nas páxinas de "Salud" de El Mundo, día dous de marzo de 1995, que leva por título "La enfermedad divina. Los estudios demuestran que existe una relación entre locura y creatividad" e como pretítulo "Psiquiatría". Efectivamente, a doutora López Blanco comenza por recordarnos, nun preámbulo ó artigo propiamente dito, como os gregos lles chamaban os poetas enfermos divinos, á vez que afirma que hoxe os estudos demostran que as persoas que padecen manía ou depresión teñen unha maior predisposición a realizar traballos creativos. Esta estudosa traíanos á memoria tamén, naquel 1995, que nos últimos vinte anos (agora, con dezaoito anos enriba, xa contaremos con outros ben distintos detalles) prestixiosas revistas psiquiátricas desvelaban como Shelley, Keats, Byron, Van Gogh ou Shuman non deberon a súa xenialidade precisamente ó deus Apolo senón a un evidente desequilibrio mental. Dende esta introdución, a doutora López Blanco pasa a nos debullar, como demostración do previamente postulado e fundamentándose no prestixios doutros estudosos e estudosas da psique humana, certas peripecias que, ó parecer, concorren en afamados creadores e creadoras no decurso do tempo: Kay Jamisón, psicóloga clínica da Universidade de California, deixounos dito na revista Scientific American que os artistas que pasaron á historia por vida excéntrica ou excéntrica morte, ademais de pola súa obra, sufriran depresión ou manía depresiva, enfermidade que hoxe resulta máis divulgada como bipolaridade. Xa a finais do século XIX, Cesare Lombroso, que se ocupou da circunstancia dos escritores suicidas, asociou xenio artístico e enfermidade mental, esquizofrenia, e concedeulles, a ambas características, a condición de hereditarias; pero non foi ata os anos setenta do século XX cando se comenzaron a utilizar as técnicas modernas de diagnóstico. En 1973 Nancy Andreasen, prestixiosa neuróloga da Universidade de Iowa, cunha entrevista a 15 escritores e a 15 individuos de vida ordinaria comproba que 10 dos escritores seguían tratamento psiquiátrico, namentras que entre os individuos do grupo control tan só dous seguían ese tipo de tratamentos; $67 \%$ fronte ó 13\%. Dez anos máis adiante a xa citada Kay Jamison, nun estudo a 47 artistas e escritores británicos, xa constatou que un 30\% estivera a tratamento por depresión, entre os que os poetas eran os que saían peor parados. Hagop Akisal, psiquiatra de orixe armenia, especialista en tratamento bipolar, encauzou un estudo a 750 pacientes que eran casos severos de manía depresiva e concluíu que os enfermos emocionais son máis creativos ca o común das xentes; pero antes de pronunciarse de modo definitivo este estudoso, foi Ruth Richards, da univesidade de Harvard, quen comprobou que se daba unha creatividade significativamente superior entre pacientes con manía moderada que a demostrada polos individuos utilizados no experimento como control. Feitas as investigacións ó revés por parte de Arnol Ludwing, da Universidade de Kentucky, sobre 1005 individuos de moi diversas profesións e biografías observadas durante trinta anos (1960-1990), publicadas en 1992 no American Journal of Psychoterapy, constátase que os que tiñan traballos creativos corrían maior risco de sufriren desequilibrio mental.

Toda esta síntese informativa, dende o valioso traballo de Myriam López Blanco, non é para asumila como dogma de fe pero tampouco é información da que se poida prescindir 
con lixeireza, porque moito pode incidir no que a nós nos ocupa o comportamento cívico e socio-afectivo de todas as sensibilidades feridas polo compromiso na procura do verso intenso e expresivo. En todo caso, facer versos, segundo as tipoloxías indagadas polos especialistas, podería entenderse como unha certa autoterapia, malia que a falta de control psicoafectivo, á marxe da función terapéutica, nos semelle que non é a mellor circunstancia -tampouco para a organización dunha maneira de vivir- para a xeración unha excelsa produción poética.

\section{RETORNO Á PALABRA LITERARIA}

De maior interese para o noso cometido resulta o artigo de Francisco Ayala en El País, en outubro de 1994, titulado "Los desdichados, los dichosos poetas", no que confesa o seu coñecemento de moitos textos poéticos, textos que recibe pola súa condición intelectual e pola súa notoriedade, entre os que son unha rareza os que alcanzan noble dimensión por un verso que salva un poema, por un poema que salva un libro. Comprobar a caída no baleiro de miles e miles de versos resulta desolador, pero máis doloroso resulta ter que atribuír catadura ridícula a esa lexión de versificadores que insisten en ostentar sen disimulo a súa vaidade castigándose con recíprocas e indebidas sátiras crueis. No Século de Ouro español proliferaban os poetas, que Cervantes, en Viaje al parnaso, cifraba en "más de vente mil sitemesinos poetas". Outra volta, rercórdanos Ayala que se podería confeccionar con facilidade unha antoloxía de sátiras, agudas algunhas, manidas outras, coas que os literatos se ladraban e mordían porque o poeta, ó revés do can que non come carne de can, pode devorar con inquina o conxénere, o colega e, moitas veces, abstraer nel a súa propia imaxe, a súa propia miserable imaxe, engadiriamos nós. Eis unha das miserias máis rexeitables por ser a miseria máis miserable (valíanos a redundancia estilística). Outra eiva, miseria á fin, creo que xa expresada, é a carencia de estima que o común da sociedade ten polos facedores de versos, unha sociedade que non aprecia os valores que poida encardinar a poesía. Se, cando a capacidade de versificar era valor recoñecido socialmente, xa o Cabaleiro do Verde Gabán (Diego de Miranda), sensato personaxe de Don Quijote de la Mancha, animaba o seu fillo máis cara ós estudos da avogacía que cara ós consagrados á "ciencia de la poesía", na actualidade, cando a sociedade é tan allea e ata oposta ó recoñecemento das artes poéticas. ¿Que valoración e consello se lles poderá dar ós poetas? Di Ayala, nas datas do mencionado artigo (outubro de 1994), que poetizar chegou a ser actividade vergonzante, que se exerce case clandestinamente; vaia miseria, de concordar e asumir, como concordamos e asumimos, coa opinión de Francisco Ayala. E non inventa nada o mencionado sabio, pola contra faise eco do que deu en ser andazo había xa algún tempo, o que veu a nacer como novo concepto ou tipoloxía coa denominación de poeta vergonzante. Pero con todo, tamén co propio Ayala, vemos que agora, coma sempre, o impulso cara á creación lírica, á marxe das certas carencias de estímulos sociais, segue actuando dende o fondo emocional e intelectual de moitos seres humanos coa esperanza de acadar o momento de que o inefable, o inexplicable, se nos revele como algo inminente. Velaí a xigantesca grandeza, no ámbito de miseria, que adorna, conforma e fortalece a quen teña a condición de poeta. Deste autor, aínda nos semella de interese salientar algunha consideración dalgún dos ensaios que conforman o libro El escritor en la sociedad de masas, cuxa primeira edición foi publicada en México no ano 1956: En "El escritor de lengua española", referíndose á importancia ou trascendencia do texto e ós seus autores, di que

La tosquedad insultante de sus errores, y el que, además, la popularidad merecida de los grandes poetas del pasado o del presente -la reverencia hacia el nombre de Milton, o hacia el de Eliot; el aplauso a Pablo Neruda- sea con tal frecuencia resultado de un equívoco o, incluso, responda a motivos miserables, hacen que el escritor se incline a menospreciar la fama. La solicita, pues -aunque sea con el mínimo acto de publicar sus escritos-, y la desprecia.

No mesmo ensaio, referíndose ó desamparo dos intelectuais e escritores, á pobreza de espíritu que comparten, tamén di que "tan 
miserable situación hiere al escritor en el centro preciso de su actividad...", ademais de insistir, ó longo deste texto e doutros do mesmo libro, na utilización do vocábulo miserable con matices diferentes pero nunca alleo ós significados da súa máis penosa semántica. No ensaio "El escritor en la sociedad de masas" observa unha clara contradición entre os sentimentos que embargan á maioría dos poetas e os cotiáns comportamentos, xa que sofren un revoltallo ou contradición entre o que representa o narcisismo de seren do oficio e unha vergonzante actitude ante a súa propia condición, ante a feble propia estima da súa obra. Con todo, entre as miserias que denuncia, as miserias que analiza, as miserias das que se delata, Francisco Ayala ten alta valoración dos poetas, dos bos poetas, que poderiamos sintetizala en palabras aproximadamente súas, cando clamaba pola xusta consideración de persoas que tenden non tanto a proporcionarse pública notoriedade, por moito que pode ser unha lexítima opción, senón a "impostar su canto con las vibraciones de ese acento personal único que proclama la autenticidad del ser".

Por poñer cabo a esas referencias, na imposible exhaustividade, aínda acudiremos ó século XIX en Galicia, ó ano 1876, que foi cando o tío Marcos da Portela (Valentín Lamas Carvajal), no seu semanario con cabeceira homónima, nunha das entregas dun texto fragmentado e sen sinatura, titulado "Dez horas pol-as nubes, viaxando en grobo", establece un diálogo cunha fermosa rapariga que lle reclamaba uns versiños da súa colleita. Deseguido, tamén lle reclama unha mostra de con que versos se dirixiría a unha rapaza á que amase ou quixese namorar, ó que o tío Marcos, botando man das cántigas do país, propuxo a seguinte copla: "Maruxiña, Maruxiña/ a do refaixo marelo,/ si t'atopo no camiño,/ non cha de valer non quero". A rapaza insístelle en que sexa unha das poesías que fan os poetas da terra, ó que agora responde que hai moitas clases de poetas e, sen cumprir co que lle reclamaba, bota man doutra cántiga popular: "Sardiñas frescas d'o mar/ quen che me dera un milleiro,/ pantrigos de Ribadavia,/ nenas d'o chau d'Amoeiro". Alporizada xa a mociña, chámalle burro ó tío Marcos e reclámalle cántigas das que fan os mellores poetas de Galicia. Entón, o escritor e xornalista ourensán sincérase, conta como foxe do compromiso e xustifica o seu comportamento:

Inda tal non dixera, cando collín a porta ¡pernas para que vos quero! Voltei á fuxir coma alma que o demo leva. ¡Non che me metía en mala barullada: si nomeaba os versiños d'un primeiro, enfurruñábase o outro, e si os lembraba todos, ¡habíache leria!

Como vemos, Lamas Carvajal dótase da oportuna retórica para criticar, coa menor acritude posible pero con decidida convicción, a miseria das enfermizas sensibilidades dos poetas, o exceso de escribidores que se autoproclaman poetas. Pero nesa denuncia tamén a si mesmo se denuncia, malia que sen pretendelo, xa que algo de ulido miserable ten a súa consideración -tamén el poeta-sobre os colegas, tanto pola referencia a aqueles que, sen mercelo, se proclaman poetas, coma pola dirixida a aqueloutros que, na plena condición de tales, teñen o ego medrado demais.

\section{ALGUNHAS CONCLUSIÓNS}

Segundo viñemos observando, dende ámbitos diversos da miseria tanto como dende miserias diversas e en ben diversas circunstancias, poderiamos concluír que moitas e de moi variado signo son as miserias que sofren os poetas, que medran nos poetas, que fabrican os poetas, que xeran os poetas, que denuncian os poetas, que redimen os poetas e redimen tamén ós poetas.

Malditos ou non, teñen sido, son e serán ben moitos os poetas, de seguro entre os mellores poetas, que teñen sufrido, sofren ou sufrirán escaseza de bens de subsistencia, chegando en ocasións demais á miseria absoluta, unha miseria que nunca debería ter lugar, nin pola condición humana -son seres humanos enganchados na vida- daquela parte da sociedade que se entrega á persecución do verso esplendoroso, nin polo producto que aportan á humanidade, ese produto que é o compango da vida para moitos, que é o relato da esperanza para outros moitos, porque a poesía enchoupa de gloria o acervo humano, se cadra tan só o acervo da pequena tribo social ou lingüística 
á que pertence cada un dos elixidos. Mísera consideración allea teñen sufrido e sufrirán lexión de vates, consideración miserable sobre os individuos e consideración miserable sobre os textos, cando non se xeraliza esa mísera consideración para anatematizar ou ignorar, que resulta ser a auténtica aldraxe, a todo o colectivo e obra da caste poética. Con frecuencia, unha saúde miserable limita a capacidade vital, cando incide de modo significativo na condición física. Máis frecuente é a carencia de saúde mental que, sometida a mil miserias, pode motivar e pode activar a creatividade, pero o desequilibrio psicoafectivo alleo da sociedade condena á soidade, conduce ó martirio. Hai miserias propias e miserias sobrevindas, miserias que veñen con toda a agresividade dende fóra e miserias intrínsecas, aquelas que nacen no máis íntimo da propia alma, incluso naqueles que carecen de alma, porque a alma sempre existe para albergar as miserias todas: aquí a envexa ante o éxito alleo, a envexa simplemente, sen referencia de insatisfeito desexo conocido, a maledicencia na seguridade de calumniar, o desprezo pola luminosidade do talento do outro, a búsqueda da mentira interesada que poida elevar, sen fundamento, a mediocridade ó éxito efémero. Retesías que xorden e que envelenan para nunca despois desapareceren de todo. A maldición dos deuses é carecer da xenerosidade que impide valorar a orixinalidade allea, a creatividade allea, o talento alleo; que impide perdoar o éxito nos outros, que infecta as psicoloxías de falta de obxectivo e sincero xuízo crítico, que se traduce na falta de control da sensibilidade. Así, falta altura de miras para desenvolverse no goce coa arquitectura lírica firmemente construída por cada vate tocado do lume das máis brillantes musas. Tampouco resulta ser cuestión menor, no combate das miserias persoais do poeta, o contraste, a contradición, entre ese orgullo devastador, destrutor de toda mesura e capacidade racional de autocrítica, e esoutra cobardía de difícil definición que é a actitude vergonzante cara ó oficio ben amado, idolatrado, ou mesmo cara á propia obra, tantas veces abaneada pola inseguridade, polo temor, pola insatisfacción co traballo realizado.

Con todo, nese ermo de inseguridades, nese lamazal de limitacións, sempre acontece o milagre porque os poetas, dende tódalas miserias, xorden coa sublime condición da expresión poética, coa superlativa palabra plurívoca na soidade e no contexto. Dende a miseria e dende as miserables condicións, o poeta estoupa nunha entrega absoluta á procura, tantas veces atopada, da revelación, da rebelión, da denuncia, da redención. O poeta pon ó dispor da humanidade unha certa capacidade de coadxuvar cos movementos do universo, a maior grandeza e xenerosidade, por moito que xa teñamos ben coñecida e recoñecida a inutilidade do verso como instrumento eficaz na batalla a prol de tódalas éticas no marco desa desexable e tantas veces lograda estética.

Desta incapacidade social, malia a demagóxica utilización do poeta e do seu verso para moi retortos obxectivos, xorde outra miseria pertinaz e perigosa que os líricos son incapaces de corrixir, nin como colectivo nin, moito menos, dende a incidencia e a actuación individual: a mísera exaltación do texto mediocre, a loubanza do autor carente de mérito, recoñecido por senrazóns extratextuais, que eleva a púlpitos que lle son alleos a mediocridade e, para magnificar o delicto, procura poñer fóra de tódolos altares cívicos e líricos a aqueloutra lexión que ten sabido usar o seu altísimo talento no servizo da luz dos astros para iluminar as escuridades terreais da humanidade.

Vigo, maio de 2013 